\title{
A novel multi-walled carbon nanotube (MWNT)-based nanocomposite for PEFC electrodes
}

\author{
S MOHANAPRIYA, K K TINTULA, S D BHAT, S PITCHUMANI and P SRIDHAR* \\ CSIR-Central Electrochemical Research Institute-Madras Unit, CSIR Madras Complex, Taramani, Chennai 600 113, India
}

MS received 20 November 2011

\begin{abstract}
A novel nanocomposite comprising MWNTs and mixed-conducting polymeric components (electronic and ionic) is prepared, characterized and investigated as a support for platinum (Pt). Nanocomposite of MWNTs and poly (3,4-ethylenedioxythiophene)-poly(styrenesulfonate) (PEDOT-PSS) is prepared by in situ polymerization and characterized using Fourier-Transform infrared spectroscopy (FT-IR), thermogravimetric analysis (TGA) in conjunction with scanning electron microscopy (SEM). Atomic force microscopy (AFM) studies are also carried out to characterize the surface topography of MWNTs/PEDOT-PSS nanocomposite. X-ray diffraction (XRD) studies reveal that MWNTs/PEDOT-PSS nanocomposite provides better backbone for the improved dispersion of Pt as evidenced by the reduced Pt crystallite size over MWNTs/PEDOT-PSS nanocomposite compared to MWNTs. Electrochemical characterization studies performed with $\mathrm{Pt} /$ nanocomposite and $\mathrm{Pt} / \mathrm{MWNTs}$ demonstrate the superior catalytic activity of Pt/nanocomposite under reduced Nafion loadings in relation to Pt/MWNTs. It is observed that mixed conducting nanoporous network of MWNTs/PEDOT-PSS composite structure promotes the catalytic activity of Pt by enhancing catalyst utilization.
\end{abstract}

Keywords. MWNTs; nanocomposite; PEFCs.

\section{Introduction}

Polymer electrolyte fuel cells (PEFCs) are promising power sources for electric vehicles and portable electronic devices due to their high efficiency, near-zero emission, fast response and low-temperature operation (Bockris and Srinivasan 1969; Gottesfeld and Zawodzinski 1997; Larminie and Dicks 2000). However, commercial acceptability of PEFCs is still associated with the cost and availability of Pt metal catalyst. Conventionally, Pt catalyst is generally supported on high surface-area carbon but recent studies suggest that physical properties of carbon support could greatly influence the electrochemical properties of fuel cell catalyst because activity of catalyst depends significantly on the size of Pt particles and their dispersion pattern over the support structure (Dicks 2006). Thus, support material exhibits a profound influence on the catalytic activity and there is an interaction existing between Pt and the support. The choice of a good catalyst support material determines the catalyst structure and functionality.

Recently, MWNTs have been proposed as promising support for Pt electrocatalyst (Li et al 2002, 2003). Earlier reports suggest that $\mathrm{Pt}$ loading could be reduced to the extent of $65 \%$ by using MWNTs in relation to Vulcan XC$72 \mathrm{R}$ carbon (Matsumoto et al 2004). It is also demonstrated that appreciable increase in Pt utilization is possible with

\footnotetext{
*Author for correspondence (psridhar55@csircmc.res.in)
}

MWNTs support grown directly on the carbon paper (Wang et al 2004). Mass activity as high as $250 \mathrm{~A} / \mathrm{mg}$ (with respect to cathode) and a peak power density of $613 \mathrm{~mW} / \mathrm{cm}^{2}$ have been achieved with MWNTs support using ultra-low Pt loading (Tang et al 2007). High surface-area and electrical conductivity, inherent size combined with hollow geometry of MWNTs help to enhance the catalytic activity of Pt (Rosca et al 2005; Wildgoose et al 2005). However, MWNTs surface is chemically inert and highly hydrophobic in nature, and therefore, requires suitable pre-treatment prior to $\mathrm{Pt}$ deposition. It is believed that surface pre-treatment creates functional groups which act as active adsorption sites for Pt. As a result, surface treatments employing different oxidizing agents such as $\mathrm{HNO}_{3}, \mathrm{HNO}_{3}-\mathrm{H}_{2} \mathrm{SO}_{4}$ mixture, $\mathrm{H}_{2} \mathrm{SO}_{4}-\mathrm{K}_{2} \mathrm{Cr}_{2} \mathrm{O}_{7}$ solution and $\mathrm{H}_{2} \mathrm{O}_{2}$ have been developed (Wildgoose et al 2005). Conversely, these harsh treatments create oxygen functionalities on the inert MWNTs surface that cause structural damage and introduce defects in the outer walls. Presence of these defects could shadow their intrinsic properties and inhibit their promise in real-life applications (Rosca et al 2005). Our earlier studies show that intrinsic structure of MWNTs promotes mass activity of Pt and pre-treatment without damaging the MWNTs is essential to attain higher Pt loading on MWNTs (Mohanapriya et al 2010). Accordingly, this study aims to increase the Pt loading on MWNTs by incorporating mixed conducting polymers with improved dispersion of Pt on MWNTs leading to better catalyst utilization.

Keeping the aforesaid facts in mind, the present study is an attempt to modify MWNTs by blending it with poly 
(3,4-ethylenedioxythiophene) (PEDOT) and polystyrene sulfonate (PSS), thereby, preserving its intrinsic structure. Pt supported on MWNTs/PEDOT-PSS nanocomposite has the advantage of high electrical conductivity of MWNTs and mixed conductivity of PEDOT-PSS polymer. Electrochemical properties and super-capacitance behaviour of PEDOT/MWNTs composites have already been demonstrated in the literature (Lota et al 2004). Improved electrochemical property is mainly due to the open mesoporous MWNTs network and easily accessible electrode/electrolyte interface. Also, it has been shown that better performing organic light emitting devices could be designed using MWNTs/PEDOT-PSS nanocomposite (Markovic et al 2006). Thus, earlier reports prove that blending MWNTs with PEDOT-PSS is useful to tune the physico-chemical properties as well as to improve the electrochemical characteristics of MWNTs (Frakowiak et al 2006; Chen et al 2009). The objective of this study is to utilize MWNTs/PEDOT-PSS nanocomposite with both electronic and ionic conductivity as an active catalyst support for PEFCs.

MWNTs/PEDOT-PSS nanocomposite promotes the number of Pt catalytic centres actively involved in the electron transfer reaction by offering good ionic and electronic pathways. Polarization data show that PEFC with MWNTs/ PEDOT-PSS nanocomposite supported Pt exhibits superior catalytic performance under optimized Nafion loading compared to PEFC with MWNTs supported Pt (Pt/MWNTs) electrodes.

\section{Experimental}

\subsection{Materials}

MWNT $>95 \%$ purity with a diameter of $15 \pm 5 \mathrm{~nm}$ and length of about $1 \mu \mathrm{m}$ was received from Nanolab. Inc. 3,4-Ethylenedioxythiophene (EDOT) was procured from Aldrich Chemicals. Chloroplatinic acid was purchased from Alfa Aesar. Sodium salt of polystyrenesulfonate (NaPSS), formaldehyde and ferric nitrate were procured from Acros Organics. Toray TGP-H-120 was procured from E-Tek (US) and Vulcan XC-72R carbon was procured from Cabot Corporation, US. Deionized (DI) water of resistivity, $18.4 \mathrm{M} \Omega$ $\mathrm{cm}$, from Millipore was used during the experiments.

\subsection{Synthesis of MWNTs/PEDOT-PSS composite}

Synthesis of MWNTs supported PEDOT-PSS composite was carried out following the procedure for in situ polymerization of conducting polymers in the presence of MWNTs (Cochet et al 2001). In a typical experiment, MWNTs (0.1 g) was dispersed in the reaction mixture using an ultrasonic bath. $0.7 \mathrm{~g}$ (4 m mol) of NaPSS was dissolved in minimum quantity of water, followed by the addition of $2.84 \mathrm{ml}$ $(10 \mathrm{~m} \mathrm{~mol})$ of EDOT monomer under continuous stirring with $\mathrm{Fe}(\mathrm{III})$ as an oxidant. $\mathrm{FeCl}_{3}\left(1.2 \mathrm{~mol} \mathrm{~L}^{-1}\right)$ was dissolved in water and then EDOT $\left(1 \mathrm{~mol} \mathrm{~L}^{-1}\right)$ was added drop by drop with intensive stirring. Nanocomposite was then filtered and washed with a large amount of water followed by washing several times with ethanol to remove the residual oxidant. At the end, the composite was washed with acetone and dried at $60{ }^{\circ} \mathrm{C}$. Proportion of the components was estimated by weighing the final product in the dried state.

\subsection{Preparation of Pt electrocatalyst}

20 wt.\% Pt/nanocomposite was prepared by impregnation of $\mathrm{Pt}$ precursor followed by reduction. Typically, $0.5 \mathrm{~g}$ of MWNTs/PEDOT-PSS dispersed in water was ultrasonicated. Required amount of aqueous solution of chloroplatinic acid was added drop wise into the resulting slurry under continuous stirring for $2 \mathrm{~h}$. In order to reduce Pt ion, an aqueous solution of formaldehyde was added and the admixture was stirred well in a round bottom flask and refluxed for $2 \mathrm{~h}$ at 80 ${ }^{\circ} \mathrm{C}$. After cooling to room temperature, resultant mass was filtered through a G4 frit crucible and dried at $60^{\circ} \mathrm{C}$. Resulting Pt/nanocomposite catalyst was used for further studies. Pt/MWNTs was prepared using similar method mentioned above.

\subsection{Physicochemical characterization}

Formation of MWNTs/PEDOT-PSS nanocomposite was confirmed by Fourier-transform infrared spectra recorded on a Thermo Nicolet, Model Nexus 670 Spectrometer. Microstructure of $\mathrm{Pt} /$ nanocomposite and Pt/MWNTs was investigated by powder X-ray diffraction (XRD). Powder diffraction patterns were recorded on an X-ray diffractometer (Model Philips Pan Analytical). The average particle size was determined from the peak broadening using Scherrer equation given below.

$$
t=\frac{0 \cdot 9 \lambda}{b \cos \theta_{\mathrm{b}}} .
$$

In (1), $t$ is the crystallite size in $\AA, \lambda$ represents the wavelength ( $1.5406 \AA$ for $\mathrm{CuK}_{\propto}$ radiation), $b$ the full-width at half maximum (FWHM) of a peak in XRD spectrum, and $\theta_{\mathrm{b}}$ the diffraction angle for the peak.

Microstructure of MWNTs/PEDOT-PSS nanocomposite was examined under scanning electron microscope (Model JEOL JSM 5400 SEM) and Pico plus (molecular imaging) AFM in tapping mode with an $n$-doped silicon tip. AFM images are plane corrected and optimally Fourier filtered using scanning probe image processor (SPIP) software (Image Metrology, Denmark). To ensure that the images shown were representative of the surface morphology, multiple images were taken at different locations and scan ranges.

\subsection{Fabrication of membrane electrode assembly (MEA)}

15 wt. \% teflonized carbon paper of $0.37 \mathrm{~mm}$ thickness was used as the backing layer. To prepare gas-diffusion layer 
(GDL), Vulcan XC-72R carbon was suspended in cyclohexane and agitated in an ultrasonic water bath for $30 \mathrm{~min}$. To this solution, $15 \mathrm{wt} \%$ poly(tetrafluroethylene) (PTFE) suspension in $2 \mathrm{~mL}$ ammonia was added with continuous agitation to form the slurry. The slurry was coated to the backing layer uniformly until required loading of $1.5 \mathrm{mg} \mathrm{cm}^{-2}$ carbon was attained. GDL thus obtained was sintered in a furnace at $350{ }^{\circ} \mathrm{C}$ for $30 \mathrm{~min}$. For the reaction layer, required amount of Pt/nanocomposite was dispersed in ethanol and ultrasonicated for $1 \mathrm{~h}$. To this dispersion, 10 wt. \% Nafion (DuPont) solution was added to bind the particles uniformly in the mixture. Obtained catalyst slurry was applied onto the GDL using brush coating method. The membrane electrode assembly (MEA) was obtained by sandwiching the pretreated Nafion-1135 membrane between the two electrodes and hot pressing at $25 \mathrm{kN}\left(60 \mathrm{~kg} \mathrm{~cm}^{-2}\right)$ at $120^{\circ} \mathrm{C}$ for $3 \mathrm{~min}$ after applying a thin layer of 1:1 solution of 5 wt. \% Nafion and isopropyl alcohol onto the surface of the electrodes.

\subsection{Electrochemical characterization}

2.6a Cyclic voltammetry: Cyclic voltammetric (CV) studies were carried out to measure the electrochemical surface area employing a potentiostat (Autolab-PGSTAT 30) in fuel cell mode. Cell anode was employed as reference and counter electrode, whereas cell cathode acts as a working electrode. Gaseous hydrogen was supplied to the anode and nitrogen was supplied to the cathode. $\mathrm{CV}$ was recorded after a run time of $2 \mathrm{~h}$. The electrode was cycled from 0 to $1 \mathrm{~V}$ to obtain a stable response. ESA of Pt catalyst was determined as below (Selvarani et al 2007):

$$
\begin{aligned}
& =\frac{Q_{\mathrm{H}}}{\text { Area of electrode }\left(\mathrm{cm}^{2}\right) \times 210 \mu \mathrm{C} \times \text { Pt loading }\left(\mathrm{mgcm}^{-2}\right)},
\end{aligned}
$$

where $Q_{\mathrm{H}}$ represents the charge associated with hydrogen adsorption, $210 \mu \mathrm{C} \mathrm{cm}^{-2}$ is the charge required to oxidize a monolayer of hydrogen on smooth platinum surface.

2.6b Polarization studies: The polarization of MEAs was done using conventional fuel cell test fixture under the experimental conditions described elsewhere (Selvarani et al 2007). In brief, MEA performance was evaluated using fuel cell fixtures with parallel serpentine flow field machined on graphite plates (Schunk Kohlenstofftechnic). After equilibration, the cell was tested at $70{ }^{\circ} \mathrm{C}$ with gaseous hydrogen at anode and gaseous oxygen at cathode at atmospheric pressure. Both the gaseous reactants were humidified before supplying them to the electrodes. The flow rates for both hydrogen and oxygen gases were kept at $1.5 \mathrm{slpm}$. Galvanostatic polarization was carried out using a LCN100-36 electronic load procured from Bitrode Corporation, US.

\section{Results and discussion}

\subsection{Structural characterization of nanocomposite}

Figure 1 depicts FT-IR spectra of MWNTs/PEDOT-PSS nanocomposite and typical PEDOT-PSS polymeric composite. It is noteworthy that $\mathrm{C}-\mathrm{C}$ and $\mathrm{C}=\mathrm{C}$ stretching of quinoidal structure and ring stretching of thiophene ring are observed between 1035 and $1516 \mathrm{~cm}^{-1}$ (Garreau et al 1999). In the spectra, peaks at $1034 \mathrm{~cm}^{-1}, 1394 \mathrm{~cm}^{-1}$, and $1489 \mathrm{~cm}^{-1}$ are due to $\mathrm{C}-\mathrm{O}-\mathrm{C}$ bond stretching of ethylenedioxy group and a set of peaks at $420 \mathrm{~cm}^{-1}$, $620 \mathrm{~cm}^{-1}$ and $820 \mathrm{~cm}^{-1}$ are assigned to the C-S bond of thiophene ring (Han et al 2007). Peaks appearing at $1200 \mathrm{~cm}^{-1}$ and $930 \mathrm{~cm}^{-1}$ due to the $\mathrm{SO}_{3}^{-}$and $\mathrm{S}-\mathrm{OH}$ stretching of PSS are observed in both the spectra (Tintula et al 2010). MWNTs/PEDOT-PSS nanocomposite shows features similar to the standard PEDOT-PSS polymeric composite. Figure 1 illustrates that these characteristic peaks are appearing in the synthesized MWNTs/PEDOT-PSS nanocomposite implying that polymers are introduced successfully into MWNTs.

Formation of MWNTs/PEDOT-PSS nanocomposite is further verified by thermal analytical studies. Figure 2 depicts data on TGA analysis for MWNTs and MWNTs/PEDOTPSS. MWNTs show a steady weight loss above $500{ }^{\circ} \mathrm{C}$. Compared to the pristine MWNTs, nanocomposite of PEDOT-PSS presents significant weight loss noticeably at around $320{ }^{\circ} \mathrm{C}$ and $450{ }^{\circ} \mathrm{C}$, which could be assigned due to the thermal degradation of PSS and PEDOT polymeric chains, respectively (Sun and Sun 2009). The earlier onset of thermal degradation and difference in the thermal properties implies successful formation of MWNTs/PEDOTPSS nanocomposite. These results also indicate that MWNTs/PEDOT-PSS nanocomposite is fairly stable up to a temperature of around $300^{\circ} \mathrm{C}$ and subsequently starts to decompose.

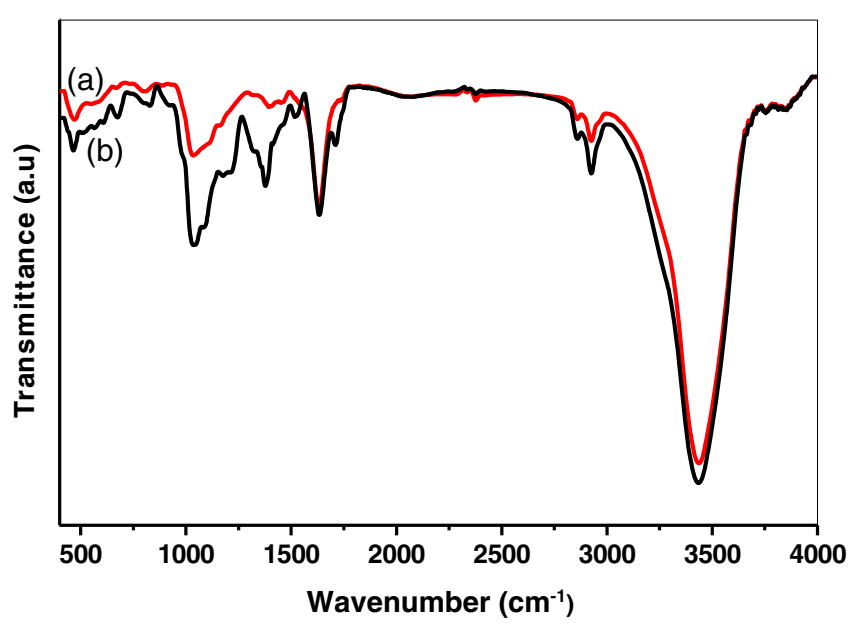

Figure 1. FTIR spectra of (a) MWNTs/PEDOT-PSS nanocomposite and (b) PEDOT-PSS polymeric composite. 
The microstructure of MWNTs/PEDOT-PSS nanocomposite is characterized by scanning electron microscopy. Surface morphology of MWNTs/PEDOT-PSS nanocomposite and MWNTs could be noticed from SEM micrographs shown in figure 3. SEM studies prove that MWNTs is blended with the conducting polymers. Figure 4 displays AFM images of MWNTs and MWNTs/PEDOT-PSS nanocomposite. It is clear from the data that MWNTs is coated by the polymer and diameter of polymer wrapped MWNTs has been considerably increased. Diameter of polymer coated MWNTs ranges from 120-150 nm whereas the original diameter is $<50 \mathrm{~nm}$. On comparing the undulations in the height profile as depicted by figures 4(c) and (d), it is obvious that MWNTs/PEDOT-PSS surface is more uniform than MWNTs. To elucidate the topographical changes

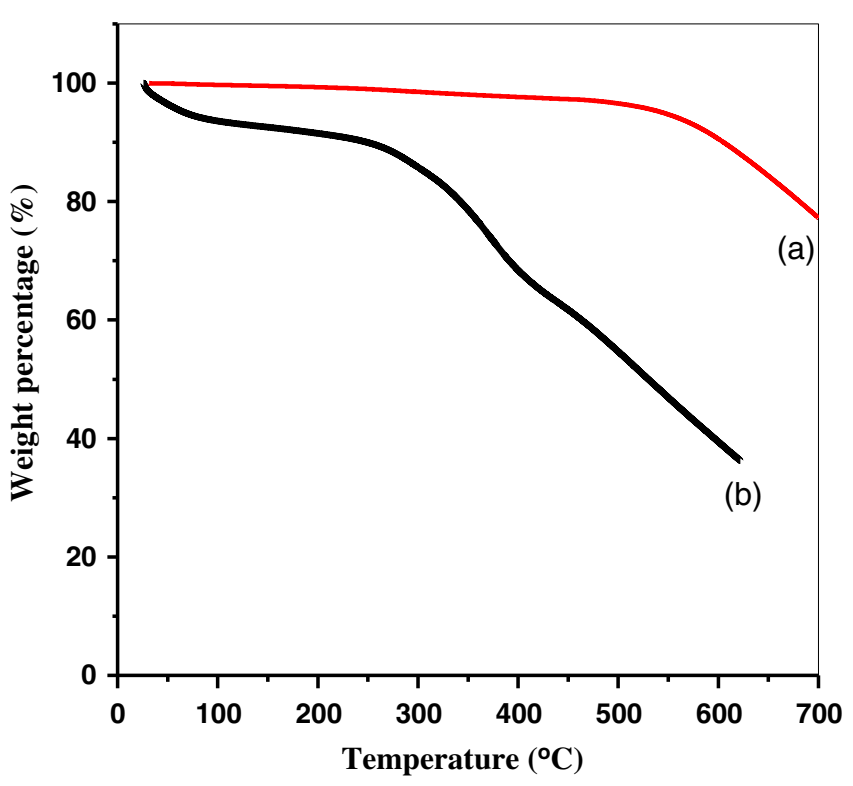

Figure 2. TGA plots for (a) MWNTs and (b) MWNTs/PEDOTPSS nanocomposite. between MWNTs and MWNTs/PEDOT-PSS nanocomposite, surface roughness $\left(S_{\mathrm{a}}\right)$ has been determined by AFM measurement. The roughness $S_{\mathrm{a}}$, estimated from the images is $28.3 \mathrm{~nm}$ and $49 \mathrm{~nm}$ for MWNTs/PEDOT-PSS nanocomposite and MWNTs, respectively.

\subsection{Catalyst characterisation}

3.2a XRD studies: Figure 5 compares XRD patterns of $\mathrm{Pt} /$ nanocomposite and $\mathrm{Pt} / \mathrm{MWNT}$ catalysts. The diffraction peak at $2 \theta$ of $25^{\circ}$ is associated with the $\left(\begin{array}{lll}0 & 0 & 2\end{array}\right)$ plane of the hexagonal structure characteristic of carbon. Pt nanoparticles are crystalline, as indicated by the characteristic peaks in the pattern. The diffraction peaks at $2 \theta$ of 40,47 and 67 are associated with the Pt (1 111$)$, (2 000$)$, and (2 200$)$ planes, respectively (Liu et al 2005). The mean particle size according to the diffraction peaks of Pt (111) is calculated using Scherrer's formula (Liu and Creager 2010). The mean particle size of Pt/nanocomposite and Pt/MWNTs is $3.9 \mathrm{~nm}$ and $5.5 \mathrm{~nm}$, respectively. It is evident from XRD studies that incorporation of the polymers favours $\mathrm{Pt}$ dispersion and facilitates reduction in the $\mathrm{Pt}$ particle size and hence helps improving the catalytic activity.

3.2b Cyclic voltammetry and polarization studies: The enhanced catalytic activity of the Pt/nanocomposite is validated through the cyclic voltammetry $(\mathrm{CV})$ and polarization studies. Figure 6 presents $\mathrm{CV}$ of $\mathrm{Pt} /$ nanocomposite and Pt/MWNTs catalysts under identical conditions. Peaks appearing from 0 to $0.4 \mathrm{~V}$ are associated with hydrogen adsorption-desorption, the columbic charge for hydrogen oxidation is a measure of electrochemically active surface area (ESA) of the catalyst. It is evident from the figure that the charge associated with Pt/nanocomposite is more compared to Pt/MWNTs. Consequently ESA is greater $\left(92 \mathrm{~m}^{2} / \mathrm{g}\right)$ for $\mathrm{Pt} /$ nanocomposite compared to Pt/MWNTs $\left(47 \mathrm{~m}^{2} / \mathrm{g}\right)$. Favourable interaction between MWNTs and polymeric

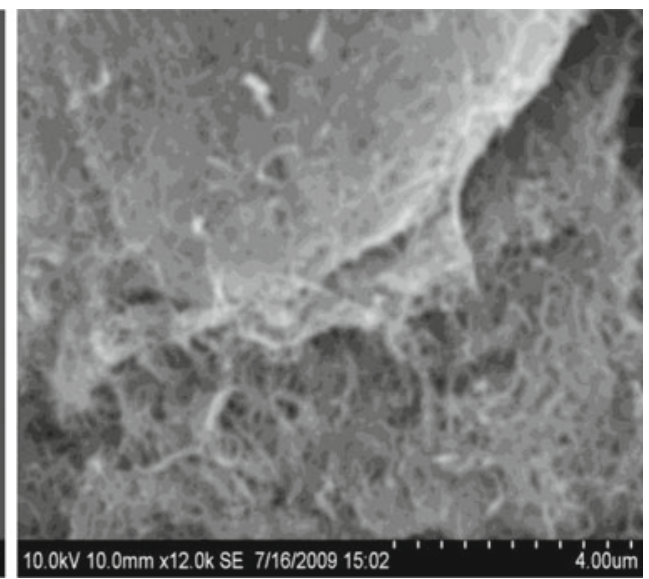

(b)

(a)

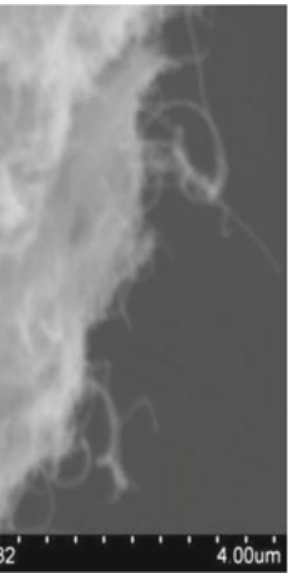

Figure 3. SEM images of (a) MWNTs and (b) PEDOT-PSS polymer composite. 

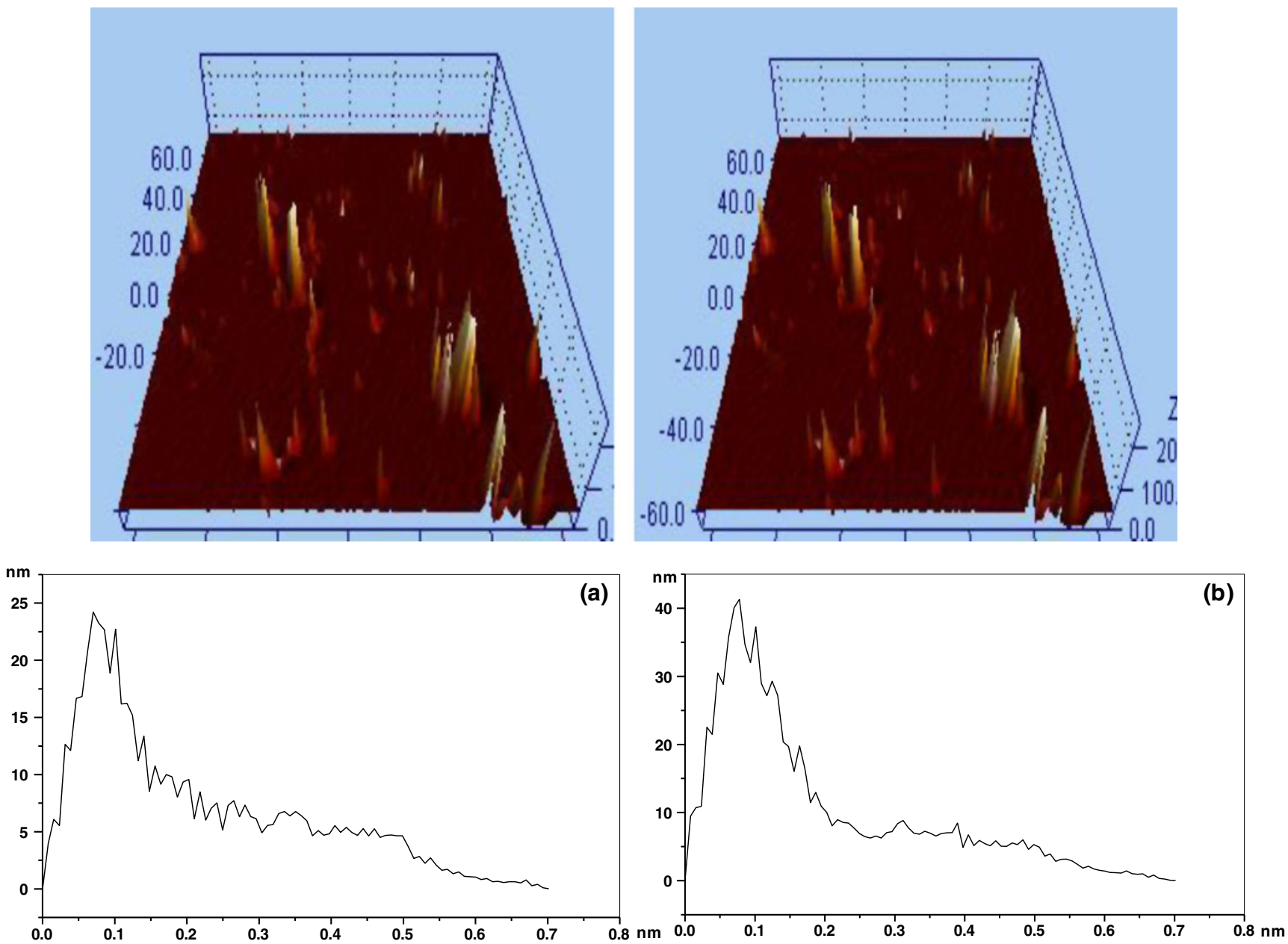

Figure 4. AFM images and corresponding height profiles of (a) MWNTs and (b) MWNTs /PEDOT-PSS nanocomposite.

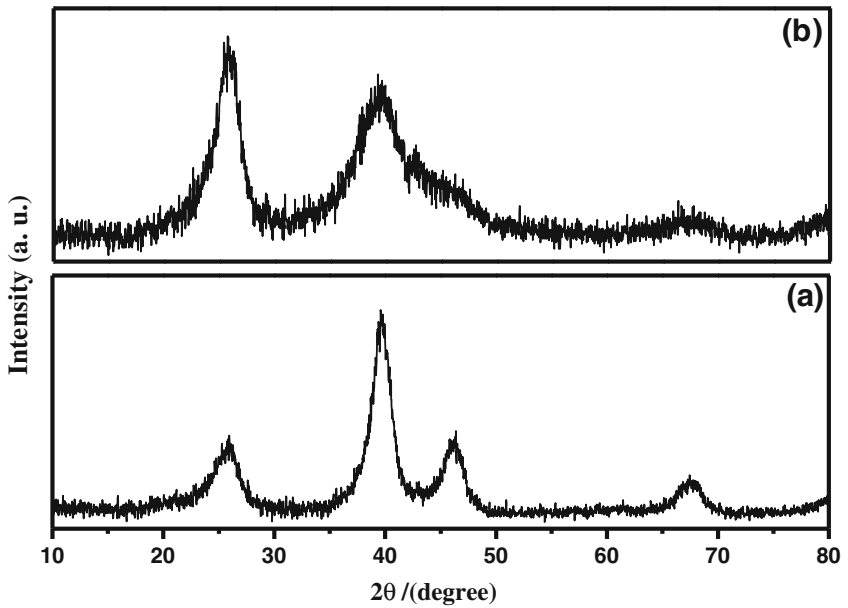

Figure 5. XRD pattern of (a) Pt/MWNTs and (b) $\mathrm{Pt} /$ nanocomposite.

chains create inter-linked composite structure which favours better Pt dispersion (Bhandari et al 2009). More number of readily available $\mathrm{Pt}$ sites associated with $\mathrm{Pt} /$ nanocomposite promotes the enhanced Pt utilization.

Figure 7 represents the polarization behaviour of $\mathrm{H}_{2}-$ $\mathrm{O}_{2}$ PEFCs comprising Pt/nanocomposite, Pt/MWNTs and $\mathrm{Pt} / \mathrm{C}$ electrodes. Comparative performance is carried out with both Pt/C and Pt/MWNTs containing 30 wt. \% Nafion in the catalyst layer. Nafion loading is varied between 7 and $30 \mathrm{wt}$. \% in both anode and cathode catalyst layers comprising $\mathrm{Pt} /$ nanocomposite. Higher performance is observed for $\mathrm{Pt} /$ nanocomposite with catalyst layer containing 30 wt. \% Nafion in relation to $\mathrm{Pt} / \mathrm{C}$ and Pt/MWNTs, while substantially improved performance is observed for $\mathrm{Pt} /$ nanocomposite with 7 wt. \% Nafion. The higher performance with minimal Nafion content in the catalyst layer (7 wt. \%) is attributed to the intrinsic ionic conductivity of the nanocomposite. The resistance associated with $\mathrm{Pt} /$ nanocomposite, Pt/MWNTs and Pt/C are calculated from the respective polarization data. It is found that the ohmic resistance associated with $\mathrm{Pt} /$ nanocomposite is lower in relation to Pt/MWNTs $\left(0.48 \Omega \mathrm{cm}^{2}\right)$ and $\mathrm{Pt} / \mathrm{C}\left(0.58 \Omega \mathrm{cm}^{2}\right)$. The resistance associated with $\mathrm{Pt} /$ nanocomposite with 7 wt.\% Nafion $\left(0.30 \Omega \mathrm{cm}^{2}\right)$ is lower than 15 wt. $\%\left(0.33 \Omega \mathrm{cm}^{2}\right)$ and 
30 wt.\% $\left(0.52 \Omega \mathrm{cm}^{2}\right)$ Nafion in the catalyst layer. This trend clearly reveals that the intrinsic ionic conductivity of the nanocomposite is advantageous in providing efficient threephase contact in spite of minimal Nafion content and these results are in agreement with our earlier studies (Tintula et al 2010).

Catalyst itself provides the ion conducting paths, increasing the number of active sites in the catalyst layer. The excess amount of Nafion may be acting as an electronic insulator, decreasing the electronic conductivity of the catalyst layer and may cause some catalyst particles to be electronically isolated. Therefore, the Nafion content in the catalyst layer is optimized as $7 \mathrm{wt}$. \% for Pt/nanocomposite catalyst. By contrast, $\mathrm{Pt} / \mathrm{C}$ and $\mathrm{Pt} / \mathrm{MWNT}$ s require significantly

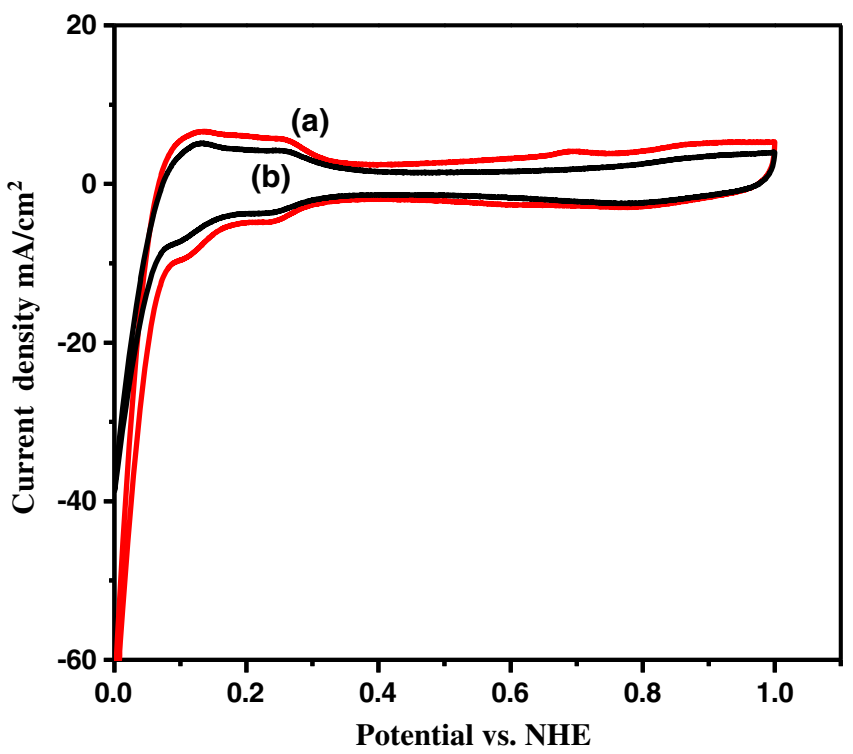

Figure 6. Cyclic voltammetric curves for (a) Pt/MWNTs and (b) $\mathrm{Pt} /$ nanocomposite in potential range between $0 \mathrm{~V}$ and $1 \mathrm{~V}$ at a scan rate of $50 \mathrm{mV} / \mathrm{s}$.

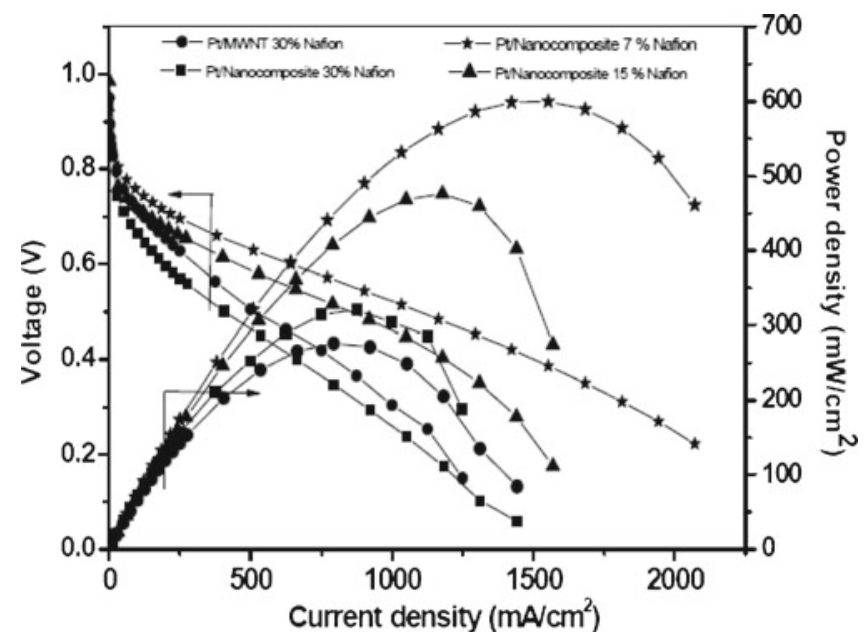

Figure 7. $I-V$ characteristics of MEAs comprising Pt/MWNTs and $\mathrm{Pt} /$ nanocomposite catalysts under varying Nafion loading. higher Nafion (30 wt. \%) in order to achieve the best performance. Hence, present study indicates that the mixed conducting characteristics of the nanocomposite could facilitate increased $\mathrm{Pt}$ utilization by the extension of proton and electron conducting paths. It can be seen that maximum peakpower density of $600 \mathrm{~mW} / \mathrm{cm}^{2}$ at a load-current density of $1500 \mathrm{~mA} / \mathrm{cm}^{2}$ is obtained for $\mathrm{Pt} /$ nanocomposite electrodes with 7 wt. $\%$ of Nafion whereas maximum peak-power densities of $480 \mathrm{~mW} / \mathrm{cm}^{2}$ and $320 \mathrm{~mW} / \mathrm{cm}^{2}$ are observed with 30 wt. $\%$ and 15 wt. \% Nafion loading, respectively. Higher performance with lower Nafion loading in the catalyst layer signifies the role of electron conducting PEDOT and proton conducting PSS polymers. It is noteworthy that ohmic loss is lowest with 7 wt. \% Nafion. Improved power density implies efficient Pt utilization for the electrochemical reaction. Both the $\mathrm{CV}$ and polarization studies prove that presence of PEDOT-PSS helps extending the three-phase contact and thus enhancing the platinum utilization.

\section{Conclusions}

Modification of MWNTs with PEDOT-PSS has been shown to improve the surface characteristics. The distinct morphology of MWNTs/PEDOT-PSS nanocomposite with mixed conductivity acts as a good support for $\mathrm{Pt}, \mathrm{Pt} /$ nanocomposite catalyst and provides improved Pt dispersion and enhanced catalyst utilization in relation to Pt/MWNTs. Porous morphology combined with intrinsic electronic and ionic conductivities of MWNTs/PEDOT-PSS nanocomposite is highly beneficial to offer readily accessible Pt catalytic sites and enhances the cell performance under reduced Nafion loading. This synergistic effect promotes the activity of $\mathrm{Pt} /$ nanocomposite by increasing the availability/mobility of ions and enhances electron-transfer characteristics.

\section{Acknowledgements}

We thank Prof. A K Shukla for many useful suggestions and a critical reading of the manuscript. Prof. V Lakshminarayanan is gratefully acknowledged for his assistance in carrying out AFM studies. Financial support from CSIR, New Delhi, through a supra-institutional project under the EFYP is gratefully acknowledged.

\section{References}

Bhandari S, Deepa M, Srivastava A K, Joshi A G and Kant R 2009 J. Phys. Chem. B113 9416

Bockris J Ò M and Srinivasan S 1969 Fuel cells: Their electrochemistry (New York: McGraw-Hill)

Chen L, Yuan C, Dou H, Gao B, Chen S and Zhang X 2009 Electrochim. Acta 542335

Cochet M, Maser W K, Benito A M, Callejas M A, Martinez M T, Benoit J M, Schreiber J and Chauvet O 2001 Chem. Commun. 1450 
Dicks A 2006 J. Power Sources 156128

Frakowiak E, Khomenko V, Jurewicz K, Lota K and Beguin F 2006 J. Power Sources 153413

Gottesfeld S and Zawodzinski T 1997 Adv. Electrochem. Sci. Eng. 5195

Garreau S, Louarn G, Buisson J P, Froyer G and Lefrant S 1999 Macromolecules 326807

Han D, Yang G, Song J, Niu L and Ivaska A 2007 J. Electroanal. Chem. 60224

Larminie J and Dicks A 2000 Fuel cell systems explained (New York: Wiley)

Li W Z, Liang C H, Qiu J S, Zhou W J, Han H M, Wei Z B, Sun G Q and Xin Q 2002 Carbon 40791

Li W Z, Liang C H, Zhou W J, Qiu J S, Zhou Z, Sun G Q and Xin Q 2003 J. Phys. Chem. B107 6292

Liu B and Creager S 2010 J. Power Sources 1951812

Liu Z, Gan L M, Hong L, Chen W and Lee J Y 2005 J. Power Sources 13973
Lota K, Khomenko V and Frackowiak E 2004 J. Phys. Chem. Solids 65571

Matsumoto T, Komatsu T, Arai K, Yamazaki T, Kijima M, Shimizu H, Takasawa Y and Nakamura J 2004 Chem. Commun. 840

Mohanapriya S, Tintula K K, Sridhar P, Pitchumani S and Shukla A K 2010 ECS Trans. 2843

Markovic M G, Matisons J G, Cervini R, Simon G P and Fredericks P M 2006 Chem. Mater. 186258

Rosca I D, Watri F, Uo M and Akasaka T 2005 Carbon 433124

Selvarani G, Sahu A K, Choudary N A, Sridhar P, Pitchumani S and Shukla A K 2007 Electrochim. Acta 524871

Sun D C and Sun D S 2009 Mater. Chem. Phys. 118288

Tang J M et al 2007 J. Phys. Chem. C111 17901

Tintula K K, Pitchumani S, Sridhar P and Shukla A K 2010 Bull. Mater. Sci. 33157

Wang C, Waje M, Wang X, Tang J M, Haddon R C and Yan Y 2004 Nano Lett. 4345

Wildgoose G, Banks C E and Richard G C 2005 Small 2182 